\title{
CT radiation dose reduction: can we do harm by doing good?
}

\author{
Mervyn D. Cohen
}

Received: 7 November 2011 / Accepted: 18 November 2011 /Published online: 3 February 2012

(C) Springer-Verlag 2011

There are two important recent publications dealing with radiation risk. In September 2011, Pediatric Radiology published a supplement containing the contents of a recent ALARA conference [1-10]. One month later, Radiology published an editorial titled "CT radiation dose: trending in the right direction" [11]. Both publications ignore an important risk of dose reduction.

In the 10 years since its inception, the term ALARA has become enshrouded with an aura of good. The achievements in pediatric dose reduction are indeed remarkable. There is now widespread awareness of the risks of cancer from radiation $[2,4,7]$. Large alliances have been formed [24]; extensive education programs on radiation dose reduction have been created $[1,2,11]$ and there are new government regulations [3]. There are many conferences on radiation safety, with the 6th ALARA conference occurring in 2011. Better methods for estimating actual patient dose are being suggested, as the limitations of indices such as CTDI and DLP are being taught $[1,3,5,6]$. Population dose is being decreased with reduction of inappropriate studies and formulation of appropriateness criteria $[1,4,7,9,10]$. Further dose reductions occur from optimizing CT techniques $[1,4,7,8]$.

Medical students are required to learn the teachings from the classic Hippocratic Oath to keep the sick from harm. In modern terms this means that physicians must consciously or subconsciously continuously weigh the benefit against the risk for any decision they make. In a recent article Huda

\footnotetext{
M. D. Cohen $(\square)$

Department of Radiology, Riley Hospital for Children, Indiana University,

702 Barnhill Drive,

Indianapolis, IN 46202, USA

e-mail: mecohen@iupui.edu
}

[13] states that for any radiological examination the benefit should exceed the radiation risk. As espoused through ALARA this means that radiologists can improve the riskto-benefit ratio by reducing radiation dose. The converse is also true; by increasing the radiation dose we worsen the risk-to-benefit ratio. Unfortunately there is another method by which we can worsen the risk-to-benefit ratio. This is by lowering the patient benefit from an imaging procedure. We can actually lower the radiation dose such that the correct diagnosis is not made from the imaging procedure. The patient receives radiation, albeit a low dose, but as the benefit to the patient is now nulled, the risk-to-benefit ratio becomes very high.

The letters $A L A$ (as low as) have been enthusiastically embraced. One even senses the development of competition among institutions to be the lowest. Phantom studies and studies that artificially add noise to clinical images have been published to support the accuracy of lower-dose images. The letters $R A$ (reasonably achievable) are the poor ignored sisters.

Radiation safety is a very complex issue. It is widely accepted that exposure to radiation increases the risk of cancer $[4,6,7,11]$. Even if we accept the proposal that there is no threshold for radiation toxicity, there remain many complex issues. As several excellent articles in the supplement discuss, there is no accurate method of measuring the actual radiation dose that is given to a patient during a CT study $[1,5,6]$. The role and limitations of the CT dose indices and the methods of determing an estimated dose are very well presented $[1,3,5,6]$.

A casual reader of the Pediatric Radiology supplement and the editorial in Radiology would be impressed by the progress made in understanding and reducing radiation dose to children. Unfortunately the articles are not well balanced. They all fall short in two very important topics. 
The very long-term cancer risks from a pediatric $\mathrm{CT}$ are clearly reviewed. Several articles do state that the risks of cancer are small and difficult to measure [6,7]. Frush [4] quotes Sternberg's article from USA Today in 2001 stating that if 1.6 million CT scans were done in 1 year in children, there would be 1,500 later deaths from radiation-induced cancer. While the risk of long-term cancer is real, the articles from the 6th ALARA conference published in the Pediatric Radiology supplement failed to place these risks into any meaningful context. The risks of cancer from CT are tiny relative to all the other risks of everyday living. For example almost 40,000 people die in road traffic accidents in the USA every year. The articles also failed to place the added risk of CT-induced cancer into any meaningful context with regard to our overall risk of getting cancer. Forty-four percent of males have a lifetime risk of getting cancer; the figure for females is $38 \%$ [13]. The radiation from a CT scan increases this risk by only a tiny fraction of a percentage.

The ALARA concept requires radiation dose to be as low as reasonably achievable. What does reasonably achievable truly mean? What is reasonably achievable? How do we define it? How do we measure it? Is it simply an indefinable concept or can it have scientific meaning? How do we know when we have reached this destination of minimal radiation dose? Does this journey have risk? Sometimes lowering dose is justified by phantom experiments that show that a target structure can still be visualized at the lower dose. Sophisticated variations of this experiment evaluate the probability of visualization at several lower doses. Clinical practice is different.

Increasing radiation causes a very small statistical future societal increased risk of cancer. This risk may or may not have a specific relevance for any individual patient having a $\mathrm{CT}$ scan. Lowering radiation for a CT scan creates a very real immediate risk to the specific patient on whom the CT scan is being performed. This is the risk of missing the correct diagnosis because the exposure factors are too low and image quality is poor [14]. There is a powerful argument that for the ill patient this risk is much greater than the theoretical tiny cancer risk 50 years later.

This risk of a missed diagnosis is very real. It is difficult to measure. After all, one may not know what one is not seeing on the image. The miss might never be known. Its consequences are difficult to quantify. These difficulties do not absolve those writing about ALARA from their responsibility to discuss the balance between cancer in the future from radiation and possible adverse events occurring immediately because low radiation has caused a missed diagnosis.

Radiology is seldom black and white. Almost every radiology impression is an opinion that expresses a probability somewhere between zero and absolute certainty. As an example, it might never be known that a CT scan with a very low dose missed an early appendicitis because of poor certainty about the presence of early subtle changes in a patient needing surgery for perforation a few days later.

As we evaluate the risk-to-benefit ratio from radiation, we are reminded in the editorial in Radiology that the longterm risk from radiation is estimated to be as low as $0.04 \%$; the article even concludes that with exposures of less than $100 \mathrm{mSv}$ "the risks of adverse health effects are either too small to be observed or are nonexistent" [11]. The risk of a missed diagnosis from radiation being too low is not known but could be very much higher than the long-term cancer risk. Nobody is studying or publishing about this problem. Just as the measurement of patient dose and the long-term risks of cancer from radiation are very difficult to measure, so are the risks from diagnostic errors from using a dose that is too low. This means that the latter risk should receive equal attention in future studies and discussions of radiation risk. The risk of going too low with radiation dose, as we try to reach the nirvana of as low as reasonable achievable, might in time be found to even exceed the risk of using slightly higher exposure factors for a CT scan.

\section{References}

1. Newman B, Callahan MJ (2011) ALARA (as low as reasonably achievable) CT - executive summary. Pediatr Radiol 41(Suppl 2): S452-S455

2. Slovis TL (2011) Where we were, what has changed, what needs doing: a decade of progress. Pediatr Radiol 41(Suppl 2):S456-S460

3. Goske MJ, Applegate KE, Bulas D et al (2011) Image gently: progress and challenges in $\mathrm{CT}$ education and advocacy. Pediatr Radiol 41(Suppl 2):S461-S462

4. Frush DP (2011) Justification and optimization of CT in children: how are we performing? Pediatr Radiol 41(Suppl 2):S467-S471

5. Strauss KJ, Goske MJ (2011) Estimated pediatric radiation dose during CT. Pediatr Radiol 41(Suppl 2):S472-S482

6. Frush DP (2011) CT dose and risk estimates in children. Pediatr Radiol 41(Suppl 2):S483-S487

7. Callahan MJ (2011) CT dose reduction in practice. Pediatr Radiol 41(Suppl 2):S488-S492

8. Mahesh M (2011) Advances in CT technology and application to pediatric imaging. Pediatr Radiol 41(Suppl 2):S493-S497

9. Macias CG, Sahouria JJ (2011) The appropriate use of CT: quality improvement and clinical decision making in pediatric emergency medicine. Pediatr Radiol 41(Suppl 2):S498-S504

10. Kaste SC (2011) Oncological imaging: tumor surveillance in children. Pediatr Radiol 41(Suppl 2):S505-S508

11. Amis SE (2011) CT radiation dose: trending in the right direction. Radiology 261:5-8

12. Huda W He W (2011) Estimating cancer risks to adults undergoing body CT examinations. Radiat Prot Dosimetry. doi:10.1093/rpd/ ncr37610.1093/rpd/ncr376

13. National Cancer Institute (2010) SEER Cancer Statistics Review 1975-2007. Lifetime risk (percent) of being diagnosed with cancer by site and race/ethnicity: males, 17 SEER areas, 2005-2007 (Table 1.15) and females, 17 SEER areas, 2005-2007 (Table 1.16). Available via http://seer.cancer.gov/csr/1975 2007/results_merged/top ic_lifetime_risk_diagnosis.pdf Accessed 29 July 2010

14. Cohen MD (2009) Pediatric CT radiation dose: how low can you go? AJR 192:1292-1303 